\title{
Profile of psychiatry in Japan
}

\section{Tsuyoshi Akiyama}

Director of the Department of Psychiatry, Kanto Medical Center, Clinical Professor of Psychiatry, Tokyo University, Japan, email akiyama@sa2.so-net.ne.jp; and member of the International Committee, Japanese Society of Psychiatry and Neurology

D uring the Edo period in Japan (1603-1867), people with mental illness were not excluded from society. Upon the introduction of European psychiatry around the 1870s, Japanese society became more discriminatory, however. In 1900 a primary law was introduced to regulate the custody of patients. In 1919 another law was approved to facilitate the establishment of public psychiatric hospitals. In 1950 the Mental Hygiene Law was enacted to prohibit home custody. However, these regulations did not assure quality of care or protect service users' rights. Also, after the Second World War, many private psychiatric hospitals were built, but this expansion of the sector was not well thought out or well coordinated. In Japan, the government regulates the private health sector only insofar as it sets standardised fees for treatments and carries out basic quality assurance.

In 1984 a scandal involving the murder of in-patients by nursing staff was reported at a psychiatric hospital. This prompted huge international pressure and the Japanese government passed the Mental Health Law in 1988. In 1995 this law was further revised to include welfare support.

\section{Service provision}

Japan operates a unique medical system in which payment for treatment is met via nationally standardised insurance; service users enjoy free access to the treatment facility of their choice. This financial assurance has sustained high accessibility to care, especially for those who fall under the Services and Supports for Persons with Disabilities Act. In consequence, numerous psychiatric clinics have emerged and in-patient treatment, including an emergency service, is available throughout the country. There are also many mental health and welfare centres, as well as rehabilitative facilities (including day treatment centres, work factories, group homes and community centres). With some variations these services are standardised and available throughout the country.

There has been a steady shift from in-patient to outpatient treatment in psychiatry in Japan. According to the World Health Organization (2005) there are 28.4 psychiatric beds per 10000 population in Japan. There remains a huge population of elderly patients who have been in hospital for many years, but for newly admitted in-patients the average length of stay is around 2-3 months.

The private sector plays an important role. In 2004, of the total of 1667 psychiatric hospitals, 1370 were private. There has been some discussion regarding the discrepancy between academic psychiatry at universities and practice within private psychiatric hospitals.

The Japanese government has recently undertaken a structural reform of psychiatric services to reduce its expenditure in this area. The Services and Supports for Persons with Disabilities Act seems to be actually causing difficulties in some respects.

Collaboration between psychiatric and medical staff needs to be developed further in Japan. The standard of education of psychiatric nurses is not high. There is not yet a national professional qualification in clinical psychology.

\section{Service users and stigma}

The rights of service users are well protected. The Community Office and the Legal Advisory Board receive complaints from the users of psychiatric facilities and work to support them.

The stigma associated with mental health problems has been lessened through the media and the internet. The media frequently report on the importance of depression, suicide prevention and post-traumatic stress disorder (PTSD), for example. Also, many people are exchanging information and experience through internet 'chat' and 'blogs'. The internet is thereby facilitating a spontaneous anti-stigma movement in the general population.

The royal family in Japan has always been supportive of people with mental health problems. The honorary president of the national Epileptic Society is a member of the royal family and the prince and princess attended the World Congress of Psychiatry in Yokohama. Recently members have spoken rather openly about mental health problems within the royal family.

\section{Current legislation}

Only designated psychiatrists can authorise the involuntary detention or treatment of people with mental health disorders. Under the Mental Health and Welfare Law, the Ministry of Health and Labor designates for such work psychiatrists with more than 5 years' experience and knowledge of the legislative procedures; those who wish to be designated must submit eight case reports, which a board examines to ascertain whether appropriate reference is made to legal procedures and clinical treatment.

According to the law, there are three main types of admission. Voluntary admission is based on consent of the patient. Medical protection admission requires the consent of a responsible relative and the assessment of one designated psychiatrist that the patient needs in-patient treatment. 
Compulsory admission requires that two independent assessments by designated psychiatrists agree the patient is exhibiting explicit danger of self-harm or harm to others.

A written report should be submitted for medical protection and compulsory admission; regular reports are also required thereafter. The law also regulates the conditions under which seclusion and restraint can be implemented.

The law gives patients the right to meet with a lawyer and to make a claim to the Community Office about treatment under any condition. An officer will visit the facility in response to a claim. Also, there is an annual inspection of psychiatric in-patient facilities.

\section{Recent developments}

\section{Terminology}

The most important recent development has been the substitution of the Japanese term for 'schizophrenia'. The term was previously translated as 'split-of-mind disease'. In 1993 the Japanese Society of Psychiatry and Neurology (JSPN) received a request from a family group to change the translation. After comprehensive discussion, in 2002 the JSPN adopted 'integration dysfunction syndrome' as the official term. This change, which coincided with the World Congress of Psychiatry in Yokohama, launched an active anti-stigma movement (Sato, 2006).

\section{Specialist qualification}

The second significant recent development has been the introduction of a specialist qualification by the JSPN. The project was approved in August 2002 and the first examination was implemented in 2006. For the specialist qualification, candidates are required to attend lectures in a wide range of areas. This system is expected to improve the quality of care provided by Japanese psychiatrists.

\section{Law on Treatment and Surveillance}

The Law on Treatment and Surveillance was implemented in July 2005. It applies to those who are mentally incapacitated and who commit a grave offence. Although there were many disputes in its passing, this law aims to provide a specialised, high-standard, rehabilitative treatment for this population. Under the law, a team composed of a judge, a psychiatrist and a psychiatric social worker decides the need for compulsory out-patient or in-patient treatment.

\section{Treatment guidelines for schizophrenia and depression}

Evidence-based guidelines for the treatment of schizophrenia and depression were developed in Japan in 2004. The American Psychiatric Association's Practice Guidelines for the Treatment of Psychiatric Disorders (Compendium 2004) was translated into Japanese and published in 2006. Psychopharmacology algorithms for schizophrenia and depression have been available since 1998.

\section{Other developments}

Other notable recent developments include the introduction of strategic planning to reduce suicides and a project of assertive community treatment.

\section{Numbers of professionals}

Japan has a population of about 128 million, for whom there are around 13000 psychiatrists, 13000 clinical psychologists, 3600 psychiatric occupational therapists and 22000 psychiatric social workers. The number of specialised psychiatric nurses is only 25 (2005 figures).

\section{Education}

Psychiatric training is included in the core undergraduate medical curriculum. The focus is on tutorial teaching and less on lectures. Bedside learning and clinical clerkship are emphasised.

For postgraduate training, there are good psychiatric textbooks available in Japanese. In the past there was no explicit standard for postgraduate training programmes; however, the JSPN now sets a clear standard for the areas to be included in the postgraduate curriculum for specialist qualification.

\section{Child psychiatry}

Relatively few facilities provide effective treatment for children and adolescents. However, several issues affect this population in particular, such as domestic violence, child abuse, withdrawal at home and a lack of motivation to participate in study or work. The government and psychiatrists are trying to develop specialists in this area.

\section{Psychotherapy}

The training for psychotherapy is not yet systematically established. Typically, senior psychiatrists will teach the basics of psychotherapy and the rest will depend on the interest of residents. The JSPN plans to provide standardised psychotherapy training opportunities.

\section{Research}

Numerous high-quality research projects in the mental health field are being conducted in Japan. Especially noteworthy for international colleagues may be studies in neuroimaging, neuropharmacology, neurophysiology and genetics. On the clinical side, social skills training has been rigorously researched. Other clinical projects are investigating cognitive therapy for various populations, the 'Rework Assist Programme' (which seeks to facilitate the rehabilitation of company employees who experience mental health problems), the introduction of electronic patient record systems and clinical paths to improve the quality of care. An active interest in anthropological psychopathology from the German and French traditions has been maintained.

\section{Professional associations}

There are around 85 associations which deal with psychiatric issues. Each usually has an annual meeting, and there are 
numerous seminars and lectures provided by these associations for both professionals and the general public.

\section{Conclusion}

Access to psychiatric treatments and services is available throughout Japan. Current priorities are the development of community care and the standardisation of professional education and training, as well as treatment. We look forward to exchanging our experiences with international colleagues.

\title{
References
}

Sato, M. (2006) Renaming schizophrenia: a Japanese perspective. World Psychiatry, 5, 54-56.

World Health Organization (2005) Mental Health Atlas 2005. WHO.

\section{Psychiatry in Cambodia: the phoenix rises from the ashes}

\author{
James MacCabe, ${ }^{1}$ Ka Sunbaunat ${ }^{2}$ and Pauv Bunthoeun ${ }^{3}$
}

${ }^{1}$ MRC Training Fellow in Health of the Public Research, Department of Psychiatry, PO 63, Institute of Psychiatry, London SE5 8AF, UK, email james.maccabe@iop.kcl.ac.uk

${ }^{2}$ Director of the National Programme for Mental Health, Ministry of Health, No. 151-153, Kampuchea Krom Blvd, Phnom Penh, Cambodia

${ }^{3}$ Deputy Director of the National Programme for Mental Health, Ministry of Health, Cambodia

ambodia is a low-income country in south-east Asia.

It covers an area of $181035 \mathrm{~km}^{2}$ and has a population of 14.5 million, of whom $42 \%$ are less than 15 years old. Life expectancy is 56.8 years and $36 \%$ of the population live on less than US $\$ 0.50$ per day. Cambodia experienced a brutal civil war and genocide in the 1970s under the Khmer Rouge regime, during which approximately 1.7 million Cambodians were killed (Chandler, 1999) and the social and medical infrastructure was almost completely destroyed. No mental health services existed throughout the conflict and subsequent Vietnamese occupation, despite the incalculable impact of the Khmer Rouge regime on Cambodians' mental health. The current political situation is more stable, although there remain concerns about human rights abuses (Khan, 2005).

\section{Historical perspective}

From 1935 to 1975, all psychiatric care was provided by a single psychiatric hospital located about $9 \mathrm{~km}$ to the south of Phnom Penh. By 1975, the patient population of the 800-bed hospital had grown to around 2000. Under the Khmer Rouge, the psychiatric hospital was destroyed and it is likely that all the patients were murdered. Across the country most professionals of all types were also killed only 43 doctors survived, none of whom were psychiatrists (Savin, 2000). Between 1975 and 1994, there were no statutory psychiatric services and no mental health training in Cambodia.

\section{Revitalisation of psychiatry in Cambodia}

In 1994, a cohort of 10 junior doctors joined the Norwegianfunded Cambodian Mental Health Training Programme; they graduated in 1998. A second cohort of 10 completed training in 2001 and, in addition, 40 psychiatric nurses have now been trained in Cambodia. The first out-patient department was opened in Phnom Penh in May 1994. The present mental health service situation in Cambodia is summarised in Box 1 .

Paradoxically, the complete destruction of the former mental healthcare system presented a unique opportunity to introduce community-based mental health services, as the often difficult tasks of reintegrating institutionalised patients into community settings and retraining staff who are accustomed to a custodial model of care were obviated in Cambodia.

Box 1 Current public sector mental health services in Cambodia

\section{Staffing}

- 26 psychiatrists

- 40 psychiatric nurses

- About 150 medical doctors have been trained in basic mental healthcare

- About 170 registered nurses have been trained in basic mental healthcare

\section{Services}

- 3 in-patient units for emergency assessment

- 18 psychiatric out-patient departments at provincial level (in general hospitals)

- 13 psychiatric units at health-centre level

- 1 child psychiatric out-patient department at national level

- 1 day-care centre at national level 